Ayurlog: National Journal of Research in Ayurved Science

\title{
Jalaukavacharana in Perianal Hematoma: A Single Case Study
}

\author{
Subhash Y. Raut ${ }^{1}$, Aditi $^{2} *$ \\ 1. Professor and HOD, drsyraut@yahoo.co.in, Mob. 9422108928 \\ 2. MS (Scholar), \\ Shalyatantra Dept, Government Ayurved College, Nagpur, Maharashtra, India, \\ *Corresponding Author: aditi.sharma019@gmail.com, Mob.9860381348
}

\section{Abstract}

A perianal hematoma is a localized collection of blood outside of blood vessels under the skin located around the border of the anus. Perianal hematomas can present over a short period of time and be extremely painful. The main symptom is pain and the swelling around the anus. Pain can range from mild to severe depending on the size of swelling that can be treated through Jalaukavacharana, a parasurgical procedure in Ayurveda. Jalaukavacharana i.e. blood- letting by jalauka is used in a variety of inflammatory conditions especially when Pitta Dosha is vitiated and gets lodged in the blood. Its mode of action depends on the injection of leech saliva into patient's tissues during the process of blood sucking. Leech saliva contains bioactive constituents which possesses antiinflammatory, analgesic, thrombolytic, vasodilator, anti-coagulant and blood circulation enhancing properties. Aim of the study is to evaluate the effect of Jalaukavcharana (Leech Therapy) in Perianal hematoma.A 42 year male patient having complains of pain and swelling in perianal region diagnosed as perianal hematoma in Shalya OPD of GAC Nagpur. Treatment of choice was Jalaukavacharana with three sittings given at alternate days and it was found to be very effective in Perianal Hematoma.

Key words: Jalaukavacharana, Leech Therapy, Perianal Hematoma, Para surgical Procedure

\section{introduction:}

In today's world; the changes in lifestyle, irregular dietary habits, stress \& strenuous work and busy agenda have led people to suffer from various diseases. One of them is perianal hematoma caused by the rupture of a small vein that drains blood from the anus. It is the result of forceful or strained bowel movement, heavy lifting, coughing or straining. Once the rupture has formed, blood quickly pools within a few hours and if left untreated, it forms a clot.

The symptoms of a perianal hematoma can present over a short period of time like pain, discomfort and swelling. Pain (varying from mild to severe) will occur, as the skin surrounding the rupture expands due to pressure. This pain will usually last even after the blood has clotted, and may continue for two to four days.

If diagnosed within the first few hours of presentation, the pooled blood 
may be evacuated using a syringe. Once the blood has clotted, it is removed via an incision over the lump under local anesthesia ${ }^{1}$. In less severe cases, only conservative management will take place that comes in the form medication and procedures to help relieve pain.

While seeking the treatment for the same, even though the people are usually motivated towards new advanced medical science and technology, Ayurveda, the science of Life; offers a better cure without side-effects like Jalaukavacharana ${ }^{2}$ i.e. leech therapy. It is a parasurgical procedure and one of the methods of bloodletting (Raktamokshana). It provides a rapid and sometimes dramatic reduction of symptoms in certain acute disorders, especially when Pitta Dosha is vitiated and gets lodged in the blood ${ }^{3}$.

Raktamokshana is indicated in various types of Kushtha (skin disorders), Visarpa (Erysipelas), Pidaka (boils and carbuncles), Vidradi (abscess), Kandu (pruritis), Arbuda (tumor), Arshas (hemorrhoids) ${ }^{4}$ etc.

Medicinal leeches have been found to secrete saliva containing about 60 different proteins. These achieve a wide variety of goals useful to the leech as it feeds, helping to keep the blood in liquid form and increasing blood flow in the affected area. Several of these secreted proteins serves as anti coagulants (such as hirudin), platelet aggravation factors (most notably apyrase, collagenase, calin), prostaglandins, vasodilators and protienase inhibitor. It is also thought that the saliva contains an anesthetic as leech bites are generally not painful $1^{5}$.

Case report: A 42 year old male was admitted in IPD of Shalya department on 30/01/2018. He had complaints of severe pain, discomfort and swelling at perianal region since 3 days. The patient had history of long driving and constipation since last week. On local examination, there was small swelling present at $9 \mathrm{O}^{\prime}$ clock position. Per rectal examination revealed no abnormality. The diagnosis was confirmed as Perianal Haematoma and treatment of choice was Jalaukavacharana, i.e. Leech Therapy. At the time of baseline assessment, a profile of hemogram, CT, BT, biochemical investigations like RBS and serological tests for HIV, HBsAg was obtained. They all were within normal limits.

Material and method: Hirudo Medicinalis leech, which is indicated for the medical use was applied locally, i.e. at the perianal hematoma.

Jalaukavacharana procedure is divided in 3 parts.

1) Purva karma:

- Purification and Activation of leech was done by putting it in bowl which contain Haridra (Turmeric) powder and water for 30 min. After this the leech was transferred to another bowl having clean water.

- Part Preparation of the Patient was done.

- Patient was put in lithotomy position; anus was cleaned by lukewarm water.

2) Pradhana karma:

- The posterior sucker of the leech was held in one hand and anterior sucker was placed at the site of application (the most prominent part of swelling) where leech was expected to be fixed.

- The posterior sucker was released from the hand which got attached to the surrounding perianal region.

- If the leech is not ready to suck the blood from the body part, then application 
of Madhu, Ghrita should be done.

- It is covered by wet cotton gauze to moist its skin.

- Around 30-70 minutes of blood sucking, Leech falls off from the site.

3) Pashchata karma:

- The site was cleaned with Triphala Churna.

- Haridra powder was applied on bleeding site. T Bandage was applied.
- Induction of emesis to the leech was done by dusting Haridra Churna on its mouth then it was put into Haridra Jala, then in pure water.

- The used leech was kept in a separate jar labelled with details of patient [name, IPD no., Date of application].

- Each alternate day, the same procedure was done.

\section{Assessment criteria:}

Clinical parameter:

1. Pain (Verbal rating scale)- Table 1:

\begin{tabular}{|l|l|l|l|}
\hline Sr. No. & Category & Scale & Score \\
\hline 1 & No pain & No complaints of pain & 0 \\
\hline 2 & Mild pain & Bearable pain requires no treatment & 1 \\
\hline 3 & Moderate pain & Pain bearable up to some extent requires treatment & 2 \\
\hline 4 & Severe pain & Unbearable pain tristurbs sleep) & 3 \\
\hline
\end{tabular}

\section{Tenderness- Table 2:}

\begin{tabular}{|l|l|l|l|}
\hline Sr. No. & Category & Signs & Score \\
\hline 1 & No tenderness & No complaints & 0 \\
\hline 2 & Mild tenderness & On firm pressure & 1 \\
\hline 3 & Moderate tenderness & On gentle pressure & 2 \\
\hline 4 & Severe tenderness & Denies touching & 3 \\
\hline
\end{tabular}

\section{Swelling Size - in cm}

Observation: Table 3:

\begin{tabular}{|l|l|l|l|l|}
\hline Title & $\begin{array}{l}\text { Before treatment } \\
(\mathbf{3 0 / 0 1 / 1 8})\end{array}$ & $\begin{array}{l}\mathbf{1}^{\text {st }} \text { sitting } \\
\mathbf{( 3 1 / 0 1 / 2 0 1 8 )}\end{array}$ & $\begin{array}{l}\mathbf{2}^{\text {nd }} \text { sitting } \\
\mathbf{( 0 2 / 0 2 / 2 0 1 8})\end{array}$ & $\begin{array}{l}\mathbf{3}^{\text {rd }} \text { sitting } \\
(\mathbf{0 4 / 0 2 / 2 0 1 8})\end{array}$ \\
\hline No. of leeches applied & N/A & 1 & 1 & 1 \\
\hline $\begin{array}{l}\text { Amount of blood } \\
\text { letting }\end{array}$ & N/A & $20 \mathrm{ml}$ & $15 \mathrm{ml}$ & $10 \mathrm{ml}$ \\
\hline Pain & 3 (Severe) & 2 (Moderate) & 1 (Mild) & 0 (No pain) \\
\hline Tenderness & 2 (Moderate) & 2 (Moderate) & 1 (Mild) & $\begin{array}{l}0 \text { (No } \\
\text { tenderness) }\end{array}$ \\
\hline Swelling Size & $1.5 \times 1.5 \mathrm{~cm}$ & $1.5 \times 1 \mathrm{~cm}$ & $1.5 \times 1 \mathrm{~cm}$ & $0.5 \times 0.5 \mathrm{~cm}$ \\
\hline
\end{tabular}




\section{Result: Table 4:}

\begin{tabular}{|l|l|l|}
\hline Title & Score before treatment & Score after treatment \\
\hline Pain & 3 & 0 \\
\hline Tenderness & 2 & 0 \\
\hline Swelling Size & $1.5 \times 1.5 \mathrm{~cm}$ & $0.5 \times 0.5 \mathrm{~cm}$ \\
\hline
\end{tabular}
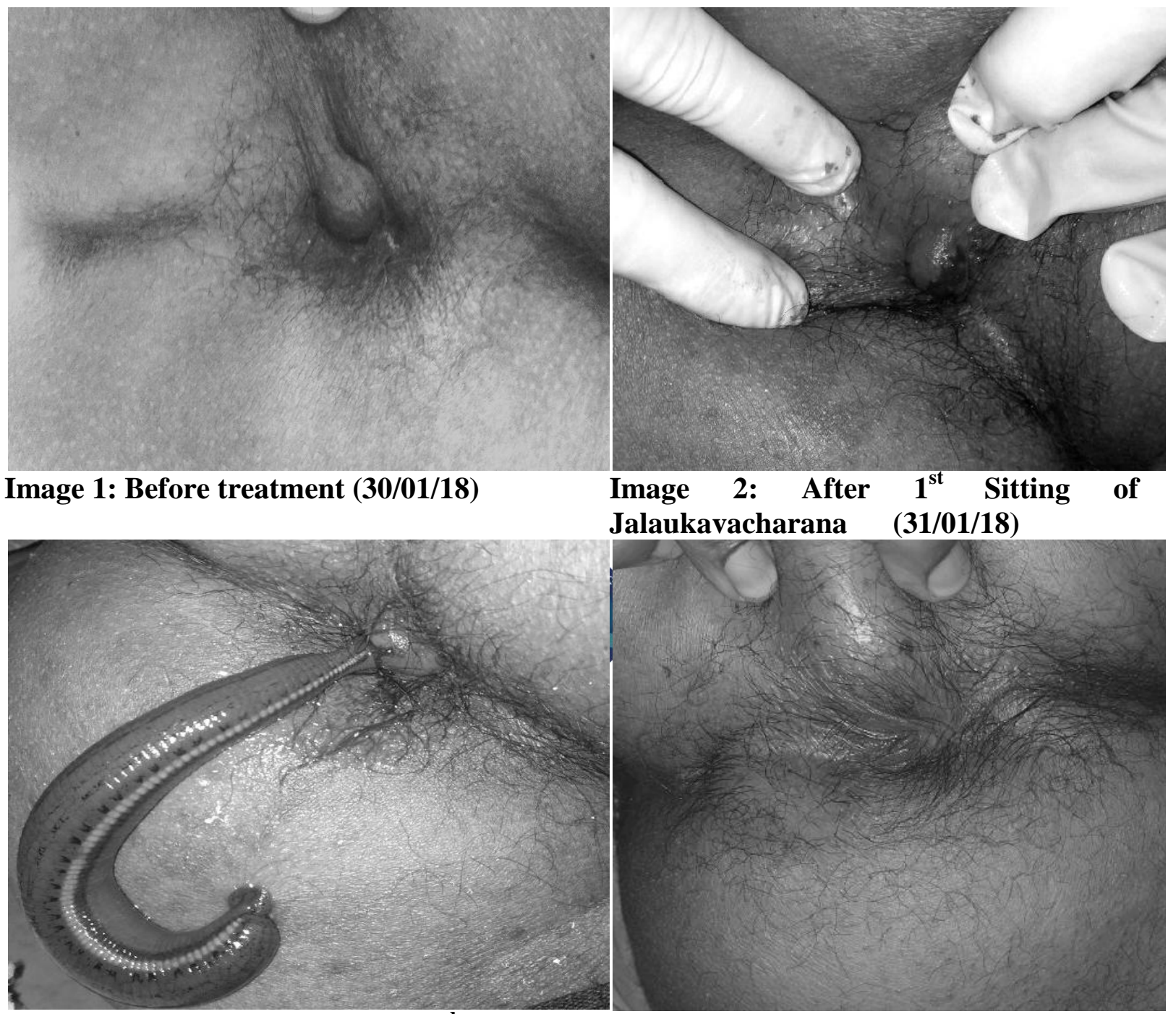

Image 3:Jalaukavcharana $2^{\text {nd }}$ Sitting Image 4: After treatment $(06 / 02 / 18)$ $(02 / 02 / 18)$

Patient got complete relief from pain at perianal region. On local examination tenderness reduced but size of perianal hematoma took more days to reduce completely as compared to pain and tenderness.

Discussion: Acharya Sushruta has elaborated leech application (Jalaukavacharana) under the topic of
Raktamokshana which can also be done by Shringa, Alabu and Siravedh ${ }^{6}$. Jalaukavacharana (Leech Therapy) is the mildest and safest methods used for bloodletting.

The acute onset of pain with a palpable mass is usually due to perianal haematoma. We have focused on analgesic and anti inflammatory effects of 
Jalaukavacharana and is found to be very effective in conditions like hematoma by reducing pain and other signs of inflammation like tenderness, redness, local temperature, swelling came to normal.

Its effect is produced by sucking blood from the site of application, reducing the local pressure hence reducing swelling as well as pain. Rather than sucking blood, leech also injects its saliva into patient's tissues during the process of blood sucking which contains various bioactive constituents possessing antiinflammatory, analgesic, thrombolytic, vasodilator, anti-coagulant and blood circulation enhancing properties. Anesthetic agents present in saliva of leech reduce pain and tenderness and give symptomatic relief. Hirudin \& calin are anticoagulant agents that effectively inhibit coagulation; has thrombolytic effect (dissolves fibrin). So, Leech application was beneficial in this case.

The complications may occur leech therapy such as wound infection by gut flora of leech, excessive bleeding etc. These may be avoided by proper knowledge and good skills of applying the leeches.

Conclusion: Leech application provides significant relief in pain, discomfort and swelling size of perianal hematoma without any side effect or complication and it can be an alternative treatment in the management of perianal hematoma in which surgery is advised and patient is not willing for the same.

\section{Reference:}

1. Sriram Bhat M, SRB's Manual of Surgery, Jaypee Brothers Medical Publishers, $4^{\text {th }}$ Edition 2013, Chapter 25, Rectum And Anal Canal, Page 1048

2. Dalhan, Nibandha Sangraha commentary on SushrutaChaukhamba Prakashan, Varanasi, edition 2013 Sutra Sthana Adhyaya 13, Page- 55-58

3. Dr. Anantram Sharma, Sushruta Samhita, Sushruta Vimarshini Hindi Vyakhya, Chaukhambha Subharti Prakashan, Edition 2015 Sutra Sthana, Adhyaya 13/6, Page no. 57

4. Charakasamhita, Chakrapani Commentray, Edited by Sri Tripati Jagadeeshwara Prasad, published by Choukamba Sanskrit series, Varanasi, 2005, Sutrasthana, Vidhishonithaadhyaya, 24th chapter $11-18^{\text {th }}$ shloka, Page-129.

5. http://leeches-medicinalis.com/theleeches/biology/

6. Prof. K. R. Shrikanth Murthy , Illustrated Sushruta Samhita Chaukhambha Orientalia Varanasi, Edition 2012, Sutra Sthana, Adhyaya 13/4-7, Page-78-79

Cite article:

Jalaukavacharana in Perianal Hematoma: A Single Case Study

Subhash Y. Raut, Aditi

Ayurlog: National Journal of Research in Ayurved Science- 2019; (7)(1): 1-5 